\title{
МОНОГОРОДА ДАЛЬНЕВОСТОЧНОГО ФЕДЕРАЛЬНОГО ОКРУГА
}

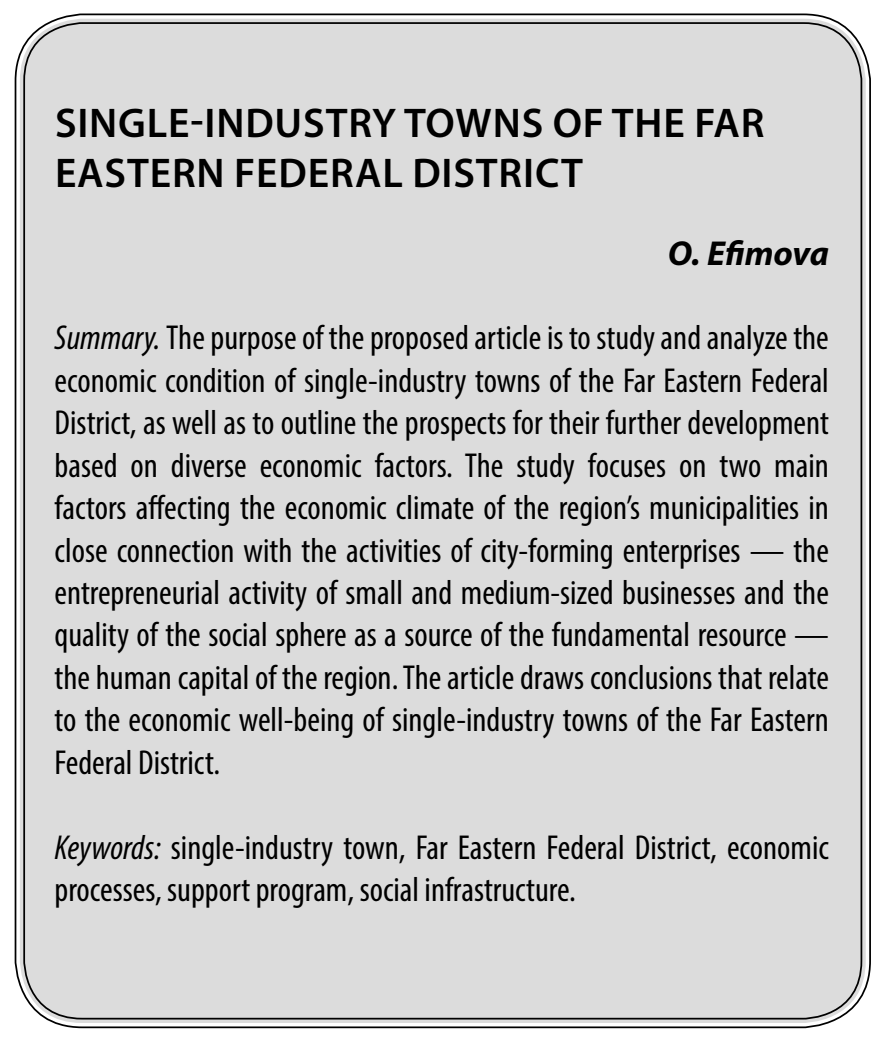

$\mathbf{M}$ оногорода появились достаточно давно и до сих пор сохраняют свою высокую значимость во многих современных странах. От обычных городов они отличаются наличием градообразующего предприятия на территории города, которое несет посильную ответственность за его обеспечение и уровень жизни населения (отвечает за состояние социальной инфраструктуры). Как правило, градообразующие предприятия формируются на территории, обладающей уникальным природным ресурсным составом (земля, вода, полезные ископаемые) и в относительно изолированной местности. Первые моногорода были основаны еще во времена Древней Руси. Они представляли собой города-крепости или монастыри, нередко размещаясь на приграничных территориях. Военные городки можно назвать современным аналогом населенных пунктов подобного типа. Постепенно такие поселки развивались, обрастали инфраструктурой, превращаясь в полноценные городские территории. Отечественные ученые-экономисты посвятили огромное количество научных трудов изучению моногородов. Посильный вклад в рассмотрение данной проблематики внесли: Е. Анимица, А.Е. Шаститко, Н. Грицких, Г.В. Кутергина, А. Маслова, М.Г. Меерович, Т. Неклюдова, Е.Е. Плисецкого, О. Смирнова и др.

\author{
Ефимова Ольга Николаевна \\ Ассистент, Финансовый университет при \\ Правительстве Российской Федерачии, г. Москва \\ onefimova@fa.ru
}

Аннотация. Цель предложенной статьи - изучить и проанализировать экономическое состояние моногородов Дальневосточного Федерального округа, а также обозначить перспективы их дальнейшего развития исходя из разносторонних экономических факторов. В фокус внимания исследования помещены два основных фактора, влияющих на хозяйственный климат муниципалитетов региона в тесной взаимосвязи с деятельностью градообразующих предприятий - предпринимательская активность субъектов малого и среднего бизнеса и качество социальной сферы как источника основополагающего ресурса - человеческого капитала региона. В статье сделаны выводы, которые касаются экономического благополучия моногородов Дальневосточного Федерального округа.

Ключевые слова: моногород, Дальневосточный Федеральный округ, экономические процессы, программа поддержки, социальная инфраструктура.

Несмотря на то, что в настоящее время существует достаточно внушительный пласт научных работ, касающихся изучения моногородов, в большей части публикаций до конца не разработанными остаются причины ухудшения ситуации в деятельности градообразующих предприятий, также крайне скупо рассматриваются возможные меры по улучшению ситуации (обеспечение регулярных поставок необходимого сырья, снижение тарифов естественных монополий, налаживание каналов сбыта, проведение модернизации производства и производственного оборудования и пр.) [8, С. 38-44].

Среди признаков, по которым можно установить принадлежность города к категории монопрофильных территориальных образований, называют: доля промышленного производства градообразующего предприятия должна быть выше $20 \%$ от общегородского объема производства; на градообразующем предприятии, как правило, трудится не менее $20 \%$ трудоспособного населения города [3, С. 62-68].

Традиционными проблемами моногородов являются демография, безработица, миграция. Ввиду этого, все чаще монопрофильные города Дальнего Востока становятся участниками ТОР, что благоприятным образом 
сказывается на их социально-экономической состоянии за счет создания центров, привлечения новых инвесторов, опорных производственных зон.

По состоянию на 2019 г. во всей России не менее 18 моногородов могут потерять свой статус монопрофильного территориального образования. В таком случае есть два альтернативных варианта выхода из кризиса: создание крупных альтернативных производств или переселение.

Резкая смена конъюнктуры мирового и отечественного рынков, исчерпание ресурсов запросто могут привести моногород в кризисное состояние. Ввиду этого, монопрофильность таких городов либо уже определяет потенциальные риски выживания, либо создает их в перспективе.

К слову, отличительными чертами моногородом Дальневосточного региона является: уникальность минерально-сырьевого потенциала; экстремальность природно-климатических условий; высокий уровень зависимости экономики монопрофильного городского поселения от уровня добычи, состояния ресурсной базы; высокая уязвимость природной среды, неравномерность инвестиционных потоков; высокий уровень негативного воздействия на природную среду, обусловленный сырьевой ориентацией промышленных центров [3, C. 62-68].

Среди моногородов в Дальневосточном федеральном округе, которые можно причислить к территориям со сложным социально-экономическим положением, выделяют: Республику Саха (Якутия) - 4, Хабаровский край - 2, Приморский край - 8, Магаданская область 1, Амурская область -2, Чукотский АО - 1 [9].

Стоит отметить, что проблемы моногородов неминуемо касаются жизни простых граждан, проживающих на их территории. Ключевая проблема традиционна: вследствие узкой специализации экономики моногорода находятся в зоне риска даже в относительно благоприятной социально-экономической ситуации [4].

Решение проблемы - диверсификация экономики монопрофильных городских образований, приумножение малого и среднего предпринимательства, которые будут производить и реализовывать различные услуги и товары. К слову, именно МСП поможет создать некий баланс в экономическом состоянии таких территорий и повысит сопротивляемость кризисам. Сегодня правительство Российской Федерации подготовило новую программу развития моногородов после досрочного закрытия прежней, признанной неэффективной. Действовать она будет с 2020 до 2024 года, а ее ежегодное финансирование запланировали на уровне 10-11 миллиардов рублей.

В целом моногорода играют особую роль в решении многих проблем социально-экономического развития. Их рассредоточенность по территории рассматриваемого округа, как и в целом по России позволяет осуществлять управление обширной территорией. Возникновение монопрофильных городских поселений было предопределено следующим обстоятельством: добыча стратегически важных для государства природных ресурсов, их первичная обработка[8, С. 38-44].

На территории Дальнего Востока развитие добывающих отраслей стало основной причиной образования моногородов. Размещение производств федерального значения в относительно небольших населенных пунктах способствовало их быстрому развитию, приросту населения. Нередко случалось так, что небольшие ранее поселения, в которых было построено градообразующее предприятие, приобретали черты города. Безусловно, такая тенденция уместна в том случае, если градообразующее предприятие не имеет проблем, стабильно производим положенный объем продукции/товаров [4].

Сравнение темпов роста больших, средних и малых городов Дальневосточного округа на протяжении 19591989 гг. показало, что темпы роста малых городов были во многом более стремительными в том случае, если на их территории было простроено монопрофильное предприятие (города Зея, Арсеньев, Амурск, Дальнегорск) [9].

Монофункциональная структура городского хозяйства, ориентация градообразующих предприятий на федеральный, региональный или даже международные рынки сбыта определили особую зависимость моногородов от колебаний рынка. Снижение или отсутствие госзаказа неминуемо влияет на ликвидность градообразующих предприятий и социально-экономическое положение самого моногорода, т.к. последний находится в прямой зависимости от поддержки, оказываемой градообразующим предприятием. Поэтому при спаде производства сразу же возрастает социальная напряженность (снижение уровня жизни населения, рост безработицы.

Для поддержания социально-экономического состояния моногородов, градообразующие предприятия которых испытывают некие трудности с ликвидностью и общим финансовым состоянием, особое внимание уделяется развитию местного бизнес-сообщества. В Дальневосточном федеральном округе условия ведения и объем малого и среднего бизнеса, а также осуществляемая региональная поддержка сильно разнятся. При этом 
мерами региональной поддержки в округе пользуются не более $1 \%$ субъектов МСП. Причин на это несколько.

Во-первых, ограниченность средств регионального бюджета, выделяемых на поддержку бизнеса. Государство попросту не может оказать финансовую помощь всем нуждающимся предпринимателям. Во-вторых, к предпринимателям, обратившимся за помощью, предпринимаются жесткие требования по отчетности по оказанной поддержке. Предоставляя поддержку представителям МСП, власть на первое место ставит принцип бюджетной эффективности. На 1 рубль бюджетных затрат в виде налоговых субсидий или льгот, представители бизнеса обязаны принести в казну не менее 1,5 рубля дохода. Если это требование не соблюдается, то по закону предприниматель обязан вернуть государству средства, переданные ему в качестве поддержки[3, С. 62-68].

Субсидирование затрат предпринимателя на приобретение нового оборудования, также подлежит строжайшей отчетности и должно сопровождаться четким перечнем документов. Любая ошибка в ведении документации может привести предпринимателя к статье «Мошенничество», за которую грозит уголовная ответственность. Многие предприниматели попросту побаиваются связываться с государством, предпочитая решать свое проблемы с бизнесом самостоятельно.

Не менее важной причиной можно назвать нежелание представителей МСП раскрывать государству информацию о своем бизнесе, что они будут вынуждены сделать в случае обращения к органам власти за получением поддержки.

В условиях кризиса при таких настроениях бизнеса реализовать нацпроект будет крайне непросто. Представителям МСП в регионах страны требуется адресная помощь, коренной пересмотр подхода к самой системе частного предпринимательства, с осознанием, что мелкий бизнес - неотъемлемая часть рыночной экономики, без которой она попросту не сможет нормально функционировать. Кроме предоставления займов, субсидий, гарантий власть должна создать благоприятные условия для работы малых и средний предприятий. Практика рассмотренных нами регионов в части оказания поддержки субъектам МСП показывает, что такая поддержка требует системного, комплексного подхода, включающего меры административного, финансового, консультационного и информационного характера. Поэтому сегодня важно изучить и перенять успешный опыт развитых мировых стран в этом вопросе, соотнеся его с реалиями жизни российских регионов[8, С. 38-44].

Достаточно перспективным вариантом поддержки МСП моногородов считается создание территорий опе- режающего развития (далее ТОР). Согласно действующему законодательству создание ТОР в моногородах Дальневосточного федерального округа будет уместным в таких случаях, как: на территориях моногородов, имеющих сложное социально-экономическое положение, включённых в перечень моногородов, утверждённым распоряжением Правительства № 1398-р; на территориях закрытых административно-территориальных образований (ЗАТО) Дальневосточного федерального округа (поправки от 1 января 2016 года); на территориях моногородов Дальневосточного федерального округа, в которых имеются риски ухудшения социально-экономического положения, и моногородов со стабильной социально-экономической ситуацией (поправки от 1 января 2017 года).

Главная цель создания ТОР сводится к формированию благоприятных условий для привлечения в моногорода сторонних инвестиций, обеспечения социально-экономического развития и создания комфортных условий для жизни местного населения. Для резидентов ТОР предусмотрен перечень налоговых льгот, в числе которых 5-летняя нулевая ставка по налогу на прибыль соответствующих организаций, пониженные отчисления по страховым взносам в течение 10 лет (около 7,6\%) в государственные внебюджетные фонды [8, С. 38-44].

В 2019 г. в рамках проекта «Моделирование сценариев пространственного развития Сибири и Дальнего Востока России до 2030...» М.В. Фомин провел исследование, которое позволило ему убедиться, что для процветания моногородов важна поддержка не только градообразующих предприятий, но и любых других предприятий и организаций, локализованных на территории моногородов.

Минвостокразвития доработало программу развития Дальневосточного федерального округа (ДФО) и внесло ее в правительство в обновленном формате. Документ станет частью Стратегии пространственного развития РФ, а не отдельной нацпрограммой.

В течение 2019 года министерство разрабатывало Национальную программу развития Дальнего Востока и в ходе Восточного экономического форума в сентябре представило ее президенту. Глава государства в целом одобрил документ и поручил уточнить источники финансирования. По поручению президента была разработана программа территориального развития ДФО до 2024 года и на перспективу до 2035 года. Первоначально ее называли «Национальная программа развития Дальнего Востока [3, С. 62-68].

В конце декабря правительство РФ утвердило план реализации Стратегии пространственного развития 
до 2025 года. Согласно плану, Минвостокразвития, Минэкономразвития и другие органы исполнительной власти до декабря 2020 года должны внести изменения в Стратегию социально-экономического развития Дальнего Востока и Байкальского региона на период до 2025 года, которая была утверждена в 2009 году. Таким образом, программа станет частью обновленной региональной стратегии, а не отдельным документом. Как отметили в министерстве, это позволит обеспечить взаимосвязь государственных программ и национальных проектов по территориальному принципу [4].

Рассмотрим особенности программы поддержки моногородов. Как отмечено в отчете Счетной палаты РФ, в прежней программе «мероприятия по поддержке моногородов не решили ключевую задачу роста благополучия их жителей». Огрехи планируют исправить в новом документе. В приоритете программы - привлечение инвестиций и создание новых рабочих мест в моногородах. Важна диверсификация экономики [9]. Для этого Фонд развития моногородов (ФРМ) РФ создал особые меры поддержки предпринимателей. В частности, им предлагают получить займы от пяти до 250 миллионов рублей под ноль процентов годовых. А если сумма выше - то под пять. Однако с начала действия этого предложения, субъекты малого и среднего предпринимательства (СМСП) Дальнего Востока не подали ни одной заявки на получение льготного займа [3, С. 62-68]. Активность в ДФО низка из-за недостаточной информированности предпринимателей.

Другая проблема в том, что людям вовсе не нужны такие огромные кредитные средства. Например, хозяйка мини-пекарни в приморском городе Спасск-Дальний не смогла получить в льготный лизинг оборудование для своего дела на миллион рублей. Ей предложили взять печи сразу на пять миллионов.

Изучая ситуацию с развитием моногородов, хотелось бы уделить внимание уровню жизни населения. Власти РФ приняли решение выделить регионам Дальнего Востока почти 15 млрд. руб. на реализацию программы льготной ипотеки - под $2 \%$ годовых. Ожидается, что в ней примут участие около 140 тыс. человек.

На реализацию программы и обеспечение льготной ставки ипотечного кредитования правительством России будут направлены средства в объеме около 14,7 млрд. рублей, а общая сумма кредитов составит до 450 млрд. рублей. Если отталкиваться от средней стоимости жилья в Дальневосточном федеральном округе (ДФО), то в программе сможет принять участие около 140 тыс. получателей «дальневосточных гектаров» и молодых семей [4].
В настоящее время в среднем по макрорегиону банки предоставляют ипотечные кредиты под процентную ставку в 9,1\%. И если брать ипотеку по такой ставке для домокомплекта (стройматериалов - ИФ) стоимостью в 3,5 млн. рублей, то в течение 20 лет стоимость такого жилья удвоится [3, С. 62-68].

Согласно проекту «Дальневосточной ипотеки», можно будет получить кредит размером до 6 млн. рублей на срок до 20 лет. Первоначальный взнос должен составлять не менее $20 \%$. Эти параметры рассчитаны исходя из среднего уровня дохода получателей «дальневосточных гектаров», а также молодых семей, чтобы их ежемесячный платеж был наиболее комфортен.

Как сообщалось, впервые о льготной ипотеке для жителей ДФО заговорили на Восточном экономическом форуме во Владивостоке. Президент РФ Владимир Путин, присутствовавший на мероприятии, поддержал озвученную инициативу и поручил правительству до 15 декабря внести изменения в законодательство России для введения в регионе 2\%-ной ипотечной ставки для указанной категории граждан. Сейчас документ проходит необходимые согласования[8, С. 38-44].

Льготная ипотека под 2\% будет доступна молодым семьям, а также участникам программы «Дальневосточный гектар». Кредит планируется выдавать сроком до 20 лет, без первоначального взноса.

Стоит отметить, что в настоящее время собственного жилья на Дальнем Востоке не имеют около 16 тыс. семей. При этом 8 тыс. человек заявили, что готовы сами построить себе жилье на «дальневосточном гектаре». Таким образом, по предварительным оценкам экспертов, благодаря программе «дальневосточная ипотека» в регионе может появиться более 7-8 тыс. домов. Эксперты уверены, что возможность обзавестись собственным жильем на льготных условиях, будет способствовать закреплению молодых специалистов в регионе[8, С. 38-44].

Это поможет развивать моногорода, города, где работают крупные предприятия. Молодежь сможет приезжать в них, брать льготную ипотеку и оставаться работать на предприятиях, развивать регион.

При этом программа поможет решить жилищный вопрос многим молодым семьям, у которых раньше не было возможности обзавестись собственным жильем.

Подобное решение позволит увеличить доступность ипотеки, а также помочь в решении жилищного вопроса молодежи, которая часто социально не защищена, не может накопить деньги даже на первоначальный 
взнос (а это в среднем около 1 млн. рублей) и вынуждена для этого брать кредит.

Жилищные проблемы часто становятся одной из причин, побуждающих молодых людей уехать из региона [9]. Поэтому для молодых специалистов это будет хороший старт. Подобная инициатива даст возможность молодым семьям получить свою жилплощадь и трудится на территории Дальнего Востока. В настоящее время льготную ипотеку ждут более 8 тыс. молодых семей, т.е. порядка 8 тыс. молодых семей попадают под действие этого решения и готовы воспользоваться льготным ипотечным кредитованием. При этом в регионе ожидают, что такая льгота повысит спрос на первичное жилье в Якутии.

Программу льготной ипотеки для дальневосточников могут запустить в декабре. В таком случае молодые семьи на Дальнем Востоке смогут реализовать свои планы на жилье уже в этом году. Сегодня рассматривается идея распространения программы 2\%-ной ипотеки в ДФО и на вторичный рынок жилья. Первоначальная идея была «оживить» первичный рынок жилья, но сегодня разрабатывается идея о переносе этого правила и на вторичный рынок жилья в субъектах Дальнего Востока. Это связано с невысоким темпом строительства нового жилья в регионе.

Причина банальна. Все дело в том, что по темпу жилищного строительства Дальний Восток, к сожалению, уступает центральным районам страны. Поэтому перспектива получить ипотеку в первичном рынке существенно объективно ниже, чем, допустим, в Москве или других городах. Этот вопрос сейчас серьезно дебатируется, рассматривается, чтобы распространить и на вторичный рынок.

Жители ДФО акцентируют внимание на том, что все меры поддержки будут бесполезны пока государство не обратит внимание на развитие социальной инфраструктуры моногородов. Сейчас подпрограмма ФРМ позволяет финансировать строительство коммуникаций лишь для инвестиционных проектов. И то, если половину расходов возьмет на себя регион[8, С. 38-44].

Программа определяет цели и основные направления социально-экономического развития Дальнего Востока как национального приоритета России. Документ должен обеспечить рост экономики Дальнего Востока, повысить качество жизни местного населения до уровня выше среднего российского, а также помочь остановить миграционный отток.

Моногорода, как известно, находятся в непосредственной зависимости от своих градообразующих предприятий. Если предприятие не испытывает никаких се- рьезных затруднений и успешно функционирует, то оно будет осуществлять и социальную политику, направленную на улучшение качества жизни населения моногорода. В противном случае, моногород не будет развиваться и, скорее всего, будет пребывать в стадии стагнации, что вызовет массовый отток населения в другие регионы и города. Учитывая это обстоятельство, представители власти должны уделять особое внимание государственной и региональной поддержке градообразующих предприятий.

К перспективным мерам поддержки могут быть отнесены следующие меры: модернизация оборудования, аудит технологических схем, снижение тарифов на транспорт, тепло - и электроэнергию и пр.

Такие незначительные меры, если рассматривать их в масштабе целого государства, помогут превратить теряющее былую конкурентоспособность предприятие в развивающееся и успешное. Особенно это актуально для моногородов, чьи градообразующие предприятия являются объектами стратегически важных для национальной экономики отраслей.

Отсутствие внимания государства к таким предприятиям может повлечь потерю перспективного инфраструктурного, кадрового, производственного потенциала региона или даже всей страны [8, С. 38-44].

К перечню стратегически важных для национальной экономики градообразующих предприятий, несомненно, стоит отнести высокотехнологичные предприятия, предприятия машиностроительного комплекса и др. Сохранение и посильное развитие суверенной технической и машиностроительной базы страны - показатель национальной безопасности, научно-технического потенциала государства.

Учитывая вышеуказанное обстоятельство, в целях повышения конкурентоспособности данных градообразующих предприятий целесообразно проводить их всестороннюю модернизацию. Это позволит обеспечить выход выпускаемых ими товаров/продуктов на международные рынки, будет способствовать наращиванию экспортного потенциала.

Стратегический интерес для современной России представляют предприятия нефтепереработки, химической промышленности, пищевой промышленности. В ДФО одним из важнейших для государства градообразующих предприятий является вертолетостроительный завод, расположенный в г. Арсеньеве Приморского края. Это предприятие специализируется на производстве военных и гражданских вертолетов разной модификации и конструкции. Сохранение его конкурентоспособности 
и значимости как авиастроительного высокотехнологичного предприятия, возможно только при непосредственной поддержке со стороны государства.

Город Железногорск (Красноярский край) также обладает достаточно уникальной производственной базой. Одно из его предприятий занимается производством космических спутников. Такое предприятия также можно назвать стратегически важным для нашего государства. Он концентрирует в себе уникальный кадровый и производственный потенциал.

Также в перечне моногородов Дальнего Востока, есть те, от нормального функционирования которых зависит бесперебойная деятельность крупнейших железнодорожных магистралей Азиатской части России. Так, например, в г. Свободный, локализованном в Амурской области, и в г. Прокопьевске Кемеровской области («Новотранс») работают крупные вагоноремонтные предприятия, а в г. Новоалтайске - вагоностроительный завод («Алтайвагон»).

Важные для железнодорожной отрасли градообразующие предприятия функционируют в городах БАМа: «Бамстроймеханизация» в г.Тында и «Мост-Восток» в г. Белогорск Амурской области. они специализируются на железнодорожном, автодорожном строительстве, возведении железнодорожных мостов.

Таким образом, на первый взгляд, невзрачные поселки городского типа или небольшие монопрофильные города Дальневосточного округа, из-за градообразующих предприятий, расположенных на этих территориях, имеют стратегическое значение для всей страны.

\section{ЛИТЕРАТУРА}

1. Аверкиева К.В., Антонов Е. В., Денисов Е. А., Фаддеев А. М. Территориальная структура городской системы севера Свердловской области // Известия Российской Академии наук. Серия географическая. — 2015.— № 4.- С. 24-38.

2. Антонов Е.В., Денисов Е. А., Ефремова В. А., Фаддеев А. М. Современные проблемы развития убывающих городов на северо-востоке Республики Коми // Вестник Московского университета. Серия 5: География. - 2014. - № 2. - С. 55-61.

3. Антонова И. С. Регионы с высокой концентрацией моногородов: проблемы повышения качества данных // Вестник КемГУ. Серия: Политические, социологические и экономические науки. - 2018.— № 3.— С. 62-68.

4. Бухвальд Е. М. Моногорода в системе стратегического планирования в России // Теория и практика общественного развития.— 2017. URL: https://doi. Org/10.24158/tipor.2017.12.16 (дата обращения: 24 июня 2019).

5. Зайнутдинов Р. Р. Моноотраслевые регионы России: определение, типологизация и перспективы развития // Экономика региона. - 2015.— № 4. C. 106-122.

6. Замятина Н.Ю., Пилясов А. Н. Инновационный поиск в монопрофильных городах: блокировки развития, новая промышленная политика и план действий: монография.- М.: ЛЕНАРД, 2015.

7. Замятина Н.Ю., Пилясов А. Н. Монопрофильные города России: блокировки и драйверы инновационного поиска // Форсайт. — 2016. — Т. 10.— № 3.— C. 53-64.

8. Зубаревич Н. В. Трансформация рынков труда российских моногородов // Вестник Московского университета. Серия 5: География.— 2017.— № 4.— C. 38-44.

9. Крючкова Е., Сапожков 0. Нацпроекты командируют в моногорода // Коммерсант.— 2019.— № 111. 